\title{
"Todo hombre en su justo lugar": la "solución" biotipológica al conflicto entre productividad y salud (Argentina, 1930-1955)
}

\author{
"Every man in his due place": the biotypological solution \\ to the conflict between productivity and health \\ (Argentina, 1930-1955)
}

Haidar, Victoria 1

\footnotetext{
${ }^{1}$ Abogada. Doctora en Ciencias Sociales. Becaria Post-Doctoral, Consejo Nacional de Investigaciones Científicas y Técnicas (CONICET). Docente, Facultad de Humanidades y Ciencias, Universidad Nacional del Litoral, Argentina. vhaidar@fcjs.unl.edu.ar
}

RESUMEN Una de las ideas en nombre de las cuales se aspira a gobernar, en el presente, la tensión entre el trabajo asalariado y la salud/enfermedad, afirma que existe una relación "virtuosa" entre la productividad organizacional y la salud de los trabajadores. Contra toda apariencia de originalidad, tal articulación no es totalmente novedosa. Ya entre 1930 y 1955 en la Argentina, una serie de médicos sostenían que, de aplicarse en los lugares de trabajo el programa de la biotipología, se conseguiría aumentar el rendimiento y disminuir los costos ligados a los accidentes y enfermedades laborales y, simultáneamente, cuidar y mejorar la vida de los trabajadores. En este artículo se analizan los temas y estrategias que configuraban el programa de la biotipología del trabajo en el país (como la selección y orientación profesional y la vigilancia del motor humano), así como las objeciones que en su momento se plantearon contra él, como forma de contribuir a la crítica de las racionalidades que, en la actualidad, apuestan a suturar el conflicto entre la productividad empresarial y la salud de los trabajadores.

PALABRAS CLAVE Historia; Biotipología; Salud Laboral; Productividad Organizacional, Argentina.

ABSTRACT One of the ideas in the name of which the connection between wage labor and health/illness is rationalized in the present asserts that there is a beneficial relationship between organizational efficiency and worker health. In contrast to its apparent originality, this articulation is not new at all. Between 1930 and 1955 in Argentina, a group of physicians upheld that if biotypology programs were implemented in the workplace, it would be possible to improve performance and reduce costs associated with labor accidents and occupational illness, while at the same time looking after and improving the lives of workers. This article analyzes the topics and strategies that formed the occupational biotypology program (such as vocational guidance, personnel selection and human motor surveillance), as well as the objections to the program formulated at the time, as a way to contribute to more contemporary critiques of the rationalities that in the present seek to placate the conflict between company productivity and worker health.

KEY WORDS History; Biotypology; Occupational Health; Efficiency, Organizational; Argentina. 


\section{INTRODUCCIÓN: RESPUESTAS HISTÓRICAS A PREGUNTAS QUE PERSISTEN}

La historiografía argentina se ha venido ocupando, en los últimos años, de estudiar los desarrollos de saberes e instituciones eugenésicas (a) en el país. Un conjunto de investigaciones se concentraron en analizar los mecanismos de circulación de ideas, los contactos de las elites intelectuales y políticas vernáculas con las europeas, la traducción de esas teorías en las políticas públicas y los aparatos del Estado, etcétera (b). Entre los temas que se han privilegiado se encuentra la biotipología (7-12). Elaborada en la Italia de la primera posguerra por Nicola Pende, un médico endocrinólogo formado en la escuela lombrosiana pero fuertemente influenciado por el pensamiento tomista, la biotipología se concibió como la disciplina encargada de efectivizar en el mundo latino -Italia, España y también la Argentina- la instrumentación práctica de la eugenesia de Francis Galton (7).

Dicha disciplina apuntaba a conocer taxonómicamente a cada individuo, a determinar la "constitución" o "biotipo" entendido como la síntesis del tipo morfológico o forma externa, el temperamento humoral y funcional, el carácter afectivo y volitivo, la inteligencia y la herencia individual (13), en la creencia de que ese conocimiento permitiría descubrir no solo las aptitudes particulares sino las "diátesis", las predisposiciones morbosas ocultas que, inexorablemente, cada cuerpo portaba.

En la Argentina, ya hacia 1923, la corporación médica exigía la aplicación del programa de Nicola Pende (9), pero el intercambio entre las elites vernáculas y las europeas se intensificó con el golpe de Estado de 1930. Esto se explica, en parte, por la simpatía que despertaban en su líder castrense, José Félix Uriburu, las ideas del fascismo italiano, cuyo proyecto político contemplaba la posibilidad de instalar un esquema de representación corporativa (14). EI mismo año del golpe, Nicola Pende llegaba al país invitado por la cátedra de Clínica Médica de la Universidad de Buenos Aires y los médicos argentinos Octavio López y Arturo Rossi (c) partían hacia Italia comisionados por Uriburu para tomar conocimiento del funcionamiento del Instituto de Bonificación y Ortogénesis de la Raza Humana instalado en Génova (d). Ese "viaje de iniciación" desembocaría en la creación, en 1932, de la Asociación Argentina de Biotipología, Eugenesia y Medicina Social, una entidad privada pero sostenida financieramente por el Estado en la que confluyeron grupos liberales y católicos; articulación que fue posible por la relativización de los fundamentos darwinianos de la eugenesia que caracterizó a la escuela de Pende (10).

El fracaso del proyecto corporativista de Uriburu no significó la liquidación del programa de los biotipólogos. Por el contrario, tanto el neoconservadurismo de la década infame como el peronismo apoyaron -si bien con importantes maticesalgunos de sus emprendimientos e ideas. La Asociación recibió la ayuda oficial del gobernador conservador (y a la sazón médico higienista) Manuel Fresco y del presidente de la Nación, Roberto M. Ortiz. En el año 1933, Arturo Rossi estableció la primera Escuela Politécnica Biotipológica, en donde se enseñó, entre otras disciplinas, medicina del trabajo. Asimismo, el Primer Congreso de Sociología y Medicina del Trabajo, organizado por la misma entidad en 1939, contó con el aval del Poder Ejecutivo. En 1943 la carrera de biotipología se oficializó, convirtiéndose al año siguiente en el Instituto Nacional de Biotipología y Materias Afines, dependiente de la Dirección de Política y Cultura Sanitaria de la Secretaría de Salud Pública de la Nación.

El discurso eugenésico no fue ajeno a la política sanitaria del peronismo. Su mayor referente intelectual, el neurocirujano Ramón Carrillo (secretario de Salud Pública entre 1946 y 1949 y luego ministro hasta su renuncia en 1954), incluía entre sus referentes intelectuales a Nicola Pende y Alexis Carrel $(9,17)$. En esos años, las funciones del Instituto se jerarquizaron institucionalmente. La aspiración de Carrillo era transformar el Instituto de Biotipología en una suerte de "Instituto Argentino del Hombre" que replicara la experiencia del que funcionó durante la Francia de Vichy (e).

En este artículo se analizan las producciones discursivas de los médicos que, como Arturo Rossi y Donato Boccia (f), cultivaron la biotipología del trabajo en el país, así como alguna de las reacciones que sus propuestas generaron 
en la corporación médica. Se nutre del archivo y entra en diálogo con la historiografía, pero su horizonte de referencia es un conjunto de problemas del presente. Si bien cercano a las preocupaciones relativas al "futuro de la naturaleza humana" (19), sus interrogantes se refieren a las formas en que se gobierna el conflicto entre las demandas capitalistas de productividad y la protección de la salud de los trabajadores.

Sabemos que, frente al peligro de la otredad -se tratara del inmigrante o del descamisado que migraba desde el campo a la ciudad-, la biotipología se articuló como una estrategia de defensa social $(10,17)$. Ese funcionamiento reactivo, sumado a la eficaz respuesta que la biotipología parecía proporcionar a la "crisis" de la población, la seducción que la modernidad tecnocrática del fascismo ejercía sobre las elites locales (20 p.274-275), así como la afinidad entre el paradigma precautorio que encarnaba y el ethos preventivo propio de la medicina social, permiten comprender por qué, aun frustrado el proyecto corporativista, la biotipología se mantuvo vigente durante, al menos, los dos primeros gobiernos peronistas.

Sin desconocer su significación frente a los problemas de la otredad y de la cantidad y calidad de la población, en este artículo la biopolítica se problematiza como un esfuerzo más por articular la exigencia de la mayor productividad del trabajo con el imperativo de conservar y mejorar la salud de la población; un imperativo que, a comienzos del siglo $\mathrm{XX}$, era sostenido desde múltiples ámbitos (la doctrina social de la Iglesia, el reformismo liberal-social, el socialismo, las ciencias del trabajo, la medicina social, etcétera).

El artículo está organizado de la siguiente manera: en el apartado I se presenta, en términos generales, la misión que la propia biotipología se encomendó respecto del trabajo para, en los apartados subsiguientes (II y III) analizar en detalle las funciones relativas a la orientación y selección profesional y la prevención de los accidentes y enfermedades del trabajo. En el punto IV se discute la concepción del trabajador que emerge del programa biotipológico, indicándose de qué manera este convive con la metáfora del "motor humano" (21) para esbozar, finalmente, una breve conclusión.

\section{LA MISIÓN DE LA BIOTIPOLOGÍA RESPECTO DEL TRABAJO}

El interés de los cultores de la biotipología en la Argentina por la población obrera y, en términos más generales, por la organización del trabajo industrial, es consustancial con la misma creación de la Asociación, una de cuyas secciones estaba constituida por la medicina del trabajo. Históricamente, los obreros constituyeron -junto a los escolares, las mujeres, los delincuentes, los militares y los jóvenes- una de las poblaciones preferidas para la acción de la higiene social, la intervención eugenésica y la experimentación de diferentes tecnologías de identificación.

Donato Boccia había comenzado a enseñar esa disciplina en 1934 en la Escuela Politécnica Biotipológica. Allí se impartían cursos teórico-prácticos orientados a formar "biotipólogos" (básicamente, maestras normales, asistentes sociales, visitadoras de higiene) para desempeñarse en diversos ámbitos: las fábricas, las escuelas, los hospitales, etcétera. Si bien se articulaba como una ciencia "polivalente", en la que se entrecruzaban la biología, la higiene, la profilaxis biosocial, la sociología política o la biología social (22 p.2), el fundamento de la biotipología era la medicina constitucionalista (23). La pretensión de colonizar el pensamiento médico explica el reclamo que, en 1949, Boccia dirigiera a la comunidad médica por la ausencia de médicos de fábrica con conocimientos biotipológicos y psicotécnicos, capaces de comandar el "ejército de solidaridad humana" formado en la Escuela de Biotipología, en las tareas de selección, vigilancia y tutela del trabajador (24 p.676). Su expectativa de que, intervención de Carrillo de por medio, esa laguna en la preparación técnica de los médicos fuera llenada por el Instituto Nacional de Biotipología y Materias Afines, no fue satisfecha. Durante la gestión de Carrillo se implementó una transformación en los contenidos de los cursos con la finalidad de imprimir a la labor de los biotipólogos, un mayor sentido práctico (25). Y, cuando hacia 1950 se constató que sus pretensiones de desempeño profesional colisionaban con las incumbencias médicas, dicho conflicto fue resuelto por medio del Poder Ejecutivo Nacional, que reglamentó la actividad, estableciendo que 
los biotipólogos podían trabajar sin control de los médicos solo cuando se dedicasen a examinar a los sanos $(10,17)$.

Si la higiene social de comienzos del siglo XX aspiraba a la limitación de las libertades en nombre de la salud pública, la medicina del trabajo tal como la concebían los biotipólogos estaba plagada de consignas y metáforas holistas (g). Ya desde su propia constitución, la Asociación Argentina de Biotipología aspiraba a convertirse en una suerte de "cerebro orientador" de la armonía física y psíquica del hombre y exhortaba a los ciudadanos a supeditar sus intereses egoístas al bien común (28). En esta dirección, Boccia (29) se refería al capital y al trabajo como fuerzas que producían la riqueza para el servicio de la colectividad nacional y la felicidad social, predicaba la armonía entre ambos factores (rechazando explícitamente la doctrina del materialismo histórico) e insistía sobre el principio de solidaridad que vinculaba a los diversos componentes del organismo social. Inspirado en las ideas del sacerdote jesuita Agustín Gemelli (h), entendía que la protección del trabajador no debía soslayar su necesaria pertenencia en una serie de colectivos más generales que lo comprendían: la familia, la nación, la religión, la oficina, etcétera.

A través de la mediación necesaria del Estado, que estaba Ilamado a "empoderar" a los biotipólogos, la biotipología se presentaba como una técnica adecuada para defender a la sociedad frente a los numerosos peligros que amenazaban con disolverla (la inmigración malsana, el comunismo, la insatisfacción del obrero) y prevenir -contrarrestando y moderando- su inevitable tendencia hacia el declive biológico y la decadencia cultural y nacional (i).

Esa vocación por organizar y defender "desde arriba" a la sociedad a través de una estrategia pretendidamente científica sería especialmente criticada por un médico "heterodoxo" (27) como Bartolomé Bosio, quien destacó la ausencia de los trabajadores en el Primer Congreso Argentino de Sociología y Medicina del Trabajo (31 p.1337). En ese foro, Rossi presentó la ambiciosa propuesta de instalar en Buenos Aires un Instituto Nacional de Biotipología y Medicina del Trabajo, similar al italiano. Si bien ese proyecto nunca se materializó, en ese mismo ámbito se plantearon una multiplicidad de propuestas dirigidas al gobierno de la población asalariada que serían recuperadas durante el peronismo, tales como la ficha biotipológica del obrero, la selección y orientación profesional, los comedores de fábrica, la instalación de un policlínico del trabajo, etcétera.

Con relación a las discusiones que tuvieron lugar en dicho congreso, Bosio $(31,32)$ observó que el proyecto de modelar "biológicamente" la producción venía a estamparse sobre una sociedad que ya estaba organizada de manera capitalista y no pretendía, tampoco, ultrapasar las determinaciones de clase. No se trataba de afectar las libertades burguesas, sino más bien de alinear las fuerzas sociales en una empresa más general que las superaba: esa empresa era, por supuesto, la "Nación" pero, asimismo, la "economía nacional", a la que la biotipología ofrecía su propia utopía productivista.

Desde esta perspectiva, el interés en los trabajadores se explica porque conformaban (junto a otras poblaciones) el "capital humano" de la Nación, el activo bio-económico-social que constituía el insumo y resorte fundamental de la economía nacional, el potencial militar del Estado, el equilibrio y el progreso de la sociedad y la cultura. Las acciones de prevención y valorización estaban justificadas por razones de "aritmética política" (33), es decir, porque de ello dependía la posición que ocupara el Estado argentino en su competencia con las otras naciones del globo.

Esa noción "holista" del capital humano -en contraposición con la valencia "individualista" que el término adquiriría con el neoliberalismo (j)- conglomeraba varios de los proyectos que, durante las décadas del 30, el 40 y el 50, se preocuparon por la cantidad y la calidad de los trabajadores y por su productividad. La demostración del valor social del capital humano permitía que la protección del trabajo se organizara con total prescindencia de razones sentimentales. De la mano de esa clase de razonamientos, y bajo la influencia de la medicina del seguro y la medicina social, comenzarían a instalarse en el país los argumentos relativos al cálculo de los costos de los accidentes, las enfermedades laborales y el ausentismo. Mientras en 1933, el entonces director de la Sanidad Militar apuntaba que cada individuo sano 
tenía un valor de "costo" (su pasado) y un "valor de producción" (su porvenir) dado por la capacidad de producir y de reproducir (34), algunos años después, Boccia (29 p.970-974) resaltaba la conveniencia de proteger al trabajo por razones económicas (en virtud de su productividad), morales (porque de esta manera se elevaba el nivel cultural y moral de las masas), sociales (ya que, como entidades vitales del engranaje social los trabajadores eran indispensables para su conservación y progreso) y también políticas: por esa vía se luchaba contra la inquietud social, el descontento y la miseria que movilizaban la "propaganda disolvente de la disciplina" y se aseguraba la armonía del capital y el trabajo que tantos beneficios prestaba a la colectividad y al Estado. Una idea semejante inspiraba el pensamiento del ministro de Salud del peronismo:

Queremos que la salud del ciudadano se cuide para que el ser logre su mayor capacidad, en beneficio propio, de los suyos y de la Nación [...] para mantener y acrecentar el poder de producción de nuestra patria, que es, en última instancia, consolidar y hacer inexpugnable su libertad y su soberanía. (35 p.99)

La agenda de la biotipología respecto del trabajo era ambiciosa. Inscripta en un paradigma productivista que comprendía al taylorismo, el fascismo y el comunismo soviético (21), se proponía vencer, con las armas de la ciencia, los límites, las resistencias, los desajustes que los cuerpos históricamente han opuesto a la utopía del rendimiento infinito. Para ello, contaba con un programa de racionalización del trabajo alternativo al taylorismo, con el que coincidía, no obstante, en cuatro fundamentos: se autopresentaba como una doctrina científica y no una mera colección de casos, presuponía la armonía en lugar de la discordia, así como la cooperación en lugar del individualismo y contra todo tradicionalismo apostaba a la maximización del rendimiento. Sin embargo, se distanciaba del método ideado por Taylor por su excesivo mecanicismo, que llevaba a descuidar el estudio del trabajador desde un punto de vista biológico. La organización del trabajo basada solo en el cronometraje olvidaba el ritmo normal de la actividad humana y los límites psicobiológicos que el cuerpo humano oponía a todo esfuerzo de normalización. La inconveniencia de ese método era particularmente notoria con relación a la mentalidad del trabajador "latino", que al estar dotado de una "marcada individualidad productiva y de marcadas tendencias creadoras" (15 p.470), no podía ser guiado como si fuera una máquina. Como alternativa, la biotipología propuso el principio de la "mejor utilización de las energías productivas en los límites fisiológicos de la actividad humana y en armonía con las capacidades y debilidades constitucionales de cada individuo" (29 p.148)

Tenemos así esbozado el programa de la biotipología del trabajo que desglosaremos en los apartados II y III. Ella se encargaría de "seleccionar" los cuerpos aptos para desempeñar diferentes funciones, finalidad a la que contribuirían exámenes clínicos, pruebas antropométricas y test psicológicos. La selección requería una tarea previa de carácter netamente pedagógico: la "orientación" profesional de niños y adolescentes, a la que estaba consagrada básicamente la psicotécnica. Y, a su vez, la determinación del biotipo permitía vigilar el "motor humano" y prevenir los accidentes y enfermedades profesionales.

\section{LA SELECCIÓN Y ORIENTACIÓN PROFESIONAL}

En el esquema del corporativismo fascista, la biotipología proponía identificar -con las armas de la biología- las aptitudes que separaban a los hombres y los determinismos que regían sus comportamientos, con la finalidad de asignarles el lugar o la función que biológicamente les correspondía dentro de la estructura orgánica de la sociedad y así obtener de ellos su máximo rendimiento y mantener el orden social (10 p.255).

El encastre entre los puestos de trabajo y los cuerpos no podía confiarse al espontaneísmo del deseo y/o a las leyes sociales de la imitación, sino que debía comandarse científicamente, si quería evitarse una acumulación en la colectividad de una "masa amorfa" de ineptos, desilusionados y descontentos, que produce poco y representa una carga para el presupuesto económico y energético de la Nación (29 p.149). 
Para realizar dicho propósito, la biotipología contaba con todo un programa, que comenzaba con la "orientación" profesional, una práctica previa a la selección dirigida a una población de niños y jóvenes que tenía por objeto aconsejarlos en la elección de una carrera. La orientación abordaba un problema básicamente "aptitudinal", que debía resolverse mediante la detección de las "aptitudes naturales" para su potencial entrenamiento. A diferencia de las "adquiridas", las aptitudes "naturales" se caracterizaban por la precocidad y espontaneidad en manifestarse, la persistencia y resistencia frente a las condiciones desfavorables, la más fácil educación y su mayor rendimiento. Podían "brotar", "precisarse" y "estabilizarse" en tanto fueran reconocidas, respetadas y cultivadas oportunamente. Pero si se les oponían obstáculos importantes o simplemente se las descuidaba durante el período de su manifestación, corrían el riesgo de languidecer: de allí la relevancia de enraizar la investigación aptitudinal -y la consecuente "orientación"- en el período escolar (36 p.246).

Por esta vía, la biotipología reforzaba las jerarquías: "existen individuos nada o poco aptitudinales, que solamente serán aptos para peones; otros [en cambio] son poliaptitudinales" (15 p.482). Pero, a cambio de ello, prometía vencer las "aparentes" dificultades que todo trabajo ofrecía, encontrando y entrenando al individuo que estaba biológicamente determinado para hacerlo.

Por su parte, la "selección" controlaba si realmente un candidato a un puesto contaba con las cualidades físico-psíquicas requeridas para él. Ese control dependía de la determinación del "VARF" de cada trabajador, sigla que representaba las cuatro cualidades que debían estudiarse para cada trabajo: velocidad, habilidad, resistencia y fuerza. Si bien este análisis había sido desarrollado en el campo de la ciencia europea del trabajo (21), se integró en los razonamientos de la biotipología a partir de la suposición de que las cuatro cualidades necesarias para el trabajo estaban íntimamente ligadas a los cuatro biotipos de Pende.

La determinación del "VARF" se hacía por medio de la ficha biotipológica, para cuya confección resultaban indispensables el estudio clínico del candidato, las pruebas experimentales orientadas a medir el esfuerzo físico y los test psicológicos. Donato Boccia elaboró una "ficha biotipológica del obrero" -que era la que venía utilizándose en el Instituto de Biotipología para clasificar a los trabajadores-, cuyo protocolo de indagación incluía (entre otros aspectos) todo lo relativo a la "herencia"; a los antecedentes morbosos y predisposición a las enfermedades del trabajador; al "biotipo morfológico"; a sus actividades "instintivas" relativas a la nutrición (cuyas dimensiones eran comida normal, frugal o abundante, entre otras) y a la propiedad (ser pródigo, ahorrativo, dadivoso, etc.); a sus "tendencias" (a conocer, a la actividad, al juego); a su conducta ética y social; a su grado de humor y de voluntad; a su inteligencia; así como una encuesta sobre su profesión actual.

La mencionada ficha, incluida en el libro de Boccia (36) que en 1947-1948 recibió el premio "Juan D. Perón", resultaba afín con el proyecto del peronismo de someter a los trabajadores a controles médicos periódicos e instaurar una ficha o carnet sanitario. En esa dirección, en 1950 se adicionó al Instituto de Biotipología la función de realizar los exámenes psicotécnicos y biotipológicos del personal que ingresara al Ministerio de Salud Pública (17 p. 327) y en 1951 se creó la Dirección de Biotipología de la Mujer que Trabaja, bajo la dirección del Dr. Miguel Goldstein (17 p.334).

Con anterioridad al peronismo, pero también en el ámbito del Estado, ya en el año 1940 la Asistencia Pública de Buenos Aires constituyó su propia Dirección de Profilaxis y Orientación del Trabajo con la finalidad de otorgar certificados de salud para los empleados y obreros de la ciudad y, asimismo, Ilevar un fichero central de patronos y empleados (37). En 1944, el decreto $N^{0} 14.538$ del Poder Ejecutivo Nacional (con fecha 3 de junio) establecía que los obreros debían ser examinados "desde el punto de vista biotipológico" antes de su ingreso al taller en carácter de aprendices, y condicionaba la obtención del permiso para trabajar a los menores, a la realización de un examen psicofísico y psicotécnico (36).

En el proyecto de identificar, registrar y clasificar a los trabajadores confluían varias instituciones, saberes y técnicas que preexistían con creces a las "fichas" que comenzaron a 
implementarse desde la Asociación de Biotipología con la finalidad de categorizar a individuos de varias poblaciones. La ficha "ortogenética escolar" fue implementada en diversos grupos de escolares que, de manera voluntaria, algunas escuelas enviaban a la Asociación para ser "fichados". Incluso, en 1935, Arturo Rossi consiguió que la Dirección General de Escuelas de la Provincia de Buenos Aires adoptara dicha ficha y que el Consejo Nacional de Educación también incorporara oficialmente la propuesta (10 p.172).

Así, la ficha del obrero no es un emergente singular del saber biotipológico, sino que guarda continuidad con toda una serie previa de tecnologías de identificación, registro y clasificación, entre las que se incluyen: la "dactiloscopía" ideada a fines del siglo XIX por Juan Vucetich, para identificar delincuentes y posteriormente utilizada en la creación de registros de inmigrantes, mendigos, vagabundos y prostitutas; los métodos de detección y clasificación de diversos grupos de escolares que implementó Víctor Mercante en la primera década del siglo XX desde la Universidad de La Plata (10); los exámenes antropométricos que realizara Alfredo Palacios (38) entre los trabajadores de los talleres del Riachuelo de la Ciudad de Buenos Aires, difundidos en su tesis del año 1922 y que diera lugar al reclamo de la jornada de ocho horas (8); las propuestas para implementar fichas sanitarias destinadas a identificar y vigilar la salud de los escolares, los lactantes, los tuberculosos, el personal del ejército, la policía y los bomberos, que venían formulándose de manera ininterrumpida desde 1910 (k); o la imposición de la más ambiciosa "ficha sanitaria universal" que, iniciada en una etapa prenatal se extendiera hasta la vida adulta (39), entre otras. En relación a los trabajadores, se había sugerido la implementación de certificados de salud para los empleados del servicio doméstico (40), un "carnet del obrero" (41) o una "ficha de aptitud física" (42) con la finalidad de evitar la comisión de fraudes que perjudicaran a los empleadores. En el plano de las prácticas, también habían comenzado a organizarse "ficheros" en algunos establecimientos fabriles. Así, por ejemplo, el médico de los talleres de la Municipalidad de Buenos Aires se congratulaba de la "gran utilidad para la clasificación moral del índice laborativo" que prestaba el "fichero" que había organizado en 1939 para asentar los datos sanitarios (exámenes médicos, incapacidades) y peripecias de la vida laboral de los 1.200 operarios ocupados, puesto que, con el "solo vistazo de la ficha", era posible determinar el rendimiento de cada uno (43 p. 470).

Como ya señalamos, la orientación y selección profesional dependían no solo de exámenes clínicos sino de test psicológicos. El desarrollo de los test correspondía a la "psicotécnica", una disciplina que había comenzado a desarroIlarse a comienzos del siglo XX en Europa, a partir de la "psicología experimental" y la "psicología aplicada", con la finalidad de estudiar la fatiga física e intelectual y luego directamente la performance en el trabajo. Los test destinados a medir la inteligencia, la atención y otras dimensiones cognitivas de los seres humanos comenzaron a probarse en el mundo del trabajo, tanto en Europa (Francia, Bélgica, Alemania) como en los EE.UU. Durante la Primera Guerra, la psicotécnica se aplicó en el ámbito militar y con su finalización, regresó a la industria y se extendió también a otras poblaciones como escolares, conductores de automóviles, jóvenes, etcétera (I).

Para aquellos profesionales formados en la escuela de Pende no era posible hacer psicotécnica sin la base de la biotipología (29 p.156) ya que, mientras aquella estudiaba la totalidad del individuo, esta era una parte especializada (la psíquica) de esa totalidad. El programa "psicotécnico" del que se nutría la biotipología era el del sacerdote Agostino Gemelli. Como puede leerse en una de las obras de Boccia (36), el mismo excedía con creces la evaluación psíquica de los individuos para comprender una serie de tópicos que por un lado, hacían a la organización de la sociedad industrial, tales como la división del trabajo y el aumento de la producción y, por otro, a la "ergonomía" o normas del trabajo: la prescripción de los movimientos más apropiados del trabajador, la armonización del ritmo de trabajo con las exigencias biológicas, entre otros aspectos.

En la Argentina, las pruebas destinadas a evaluar lo psíquico, así como las prácticas (e instituciones) de orientación y selección profesionales, preexistieron a las propuestas de la biotipología de la década del 30, y estuvieron influenciadas, principalmente, por la psicología experimental europea y estadounidense $(\mathrm{m})$. No obstante, ya 
a partir de esa década, los cruces entre esos desarrollos y los aportes de la medicina del trabajo de inspiración biotipológica fueron permanentes. El propio responsable de la sección de Orientación y Selección Profesional del Instituto de Biotipología, Ángel Olives (44), entendía a la psicotécnica como un problema de "psicología experimental" e incluía a Hugo Munsterberg (un psicólogo germano-estadounidense pionero en la aplicación de los test a la industria) entre sus referentes intelectuales. En sus trabajos de los años 1947 (36) y 1953 (45), Boccia incluía algunos avances de la psicología industrial y aplicada. Particularmente, se refería a los trabajos de Juan Kaplan (n), un médico que, desde la década del 40 e incluso con posterioridad a los gobiernos peronistas, se dedicó a desarrollar y divulgar la psicotécnica en el país. Asesor del Instituto de Psicotécnica y Orientación Profesional del Museo Social y creador de un método de selección y orientación profesional propio (que aplicó en establecimientos públicos y privados), sus investigaciones estaban inspiradas en los desarrollos de la psicología diferencial y aplicada, y en una rama especial de esta última: la psicología industrial. Pero, al mismo tiempo, Kaplan (46) sostenía, junto a los biotipólogos, la existencia de diferencias individuales en el plano de la constitución, el carácter y el temperamento, y entre sus referentes intelectuales incluía, asimismo, a Agostino Gemelli.

En el ámbito gubernamental, en el año 1944, se creó la Dirección Nacional de Aprendizaje y Orientación Profesional, en donde a partir de 1947 comenzaron a aplicarse los métodos psicotécnicos utilizados por el Instituto del Museo Social, con la finalidad de orientar a los menores aprendices en los oficios industriales. Finalmente, el plan de la Secretaría de Salud Pública contemplaba la creación de gabinetes psicotécnicos en la Sanidad Escolar y la Dirección de Higiene del Trabajo (37).

Desde el punto de vista de la biotipología, los procedimientos de selección producían un beneficio indiscutible para el empleador, ya que un trabajador bien elegido daba mayor $y$ mejor rendimiento (36 p.268). Claro que, como señalara Bosio $(31,32)$, esa clase de estrategias solo estaban dirigidas a la clase obrera y no fueron concebidas para conmover los fundamentos del orden social capitalista. Los biotipólogos en ningún caso pensaron en señalar el "justo lugar" al "hijo de un rico ganadero" ni al de un "gran accionista industrial". Para asignar compulsivamente a los trabajadores a un puesto apelaban al bienestar de la colectividad, pero sus propuestas revelaban rápidamente su carácter autoritario cuando de lo que se trataba era de afectar las libertades burguesas. Hasta el mismo Boccia (36 p.270) reconocía la dificultad de aplicar ese método por razones vinculadas con el costo de las investigaciones, el tiempo que demandaban y la imposibilidad de transformar una oficina en una sucursal de un laboratorio.

Independientemente de esos obstáculos, como veremos en el apartado siguiente, las prácticas de selección y orientación profesional eran apreciadas por los biotipólogos porque, además de asegurar a los empleadores el rendimiento efectivo de los trabajadores, contribuían a la prevención de los accidentes y enfermedades.

\section{LA REVISIÓN PERMANENTE DEL "MOTOR HUMANO" Y LA PREVENCIÓN DE ACCIDENTES Y ENFERMEDADES}

El gran atractivo que, durante una buena parte del siglo $\mathrm{XX}$, ejercieron las fichas sanitarias sobre una pléyade de médicos, pedagogos, psicólogos, etc., estaba ligado al proyecto de instalar circuitos de vigilancia que permitieran controlar de manera permanente el "potencial biológico" de la Nación. Heredera de la preocupación de la escuela criminológica italiana por la búsqueda del "criminal nato" e inspirada en la idea católica de la culpabilidad generalizada, la biotipología se autodefinía como una "clínica para sanos", cuyo fin consistía en poner a prueba la normalidad (10 p.243).

Como parte de ese proyecto, la contribución de la biotipología era doble. Por una parte, prometía vigilar a los trabajadores con la finalidad de ayudarlos a utilizar racionalmente sus aptitudes y capacidades, robustecer aquellos órganos débiles, restaurar las alteraciones latentes que la fatiga y el medio ambiente de trabajo podían haber creado; en fin, aplicarse a una labor de "revisión del motor humano" que cada trabajador 
representaba (15 p.472). Por otra parte, ese monitoreo permanente emplazaba a los sanos en una suerte de zona de sospecha de la cual resultaba imposible escapar. Nutrida por la psicotécnica, la medicina psicosomática y otros saberes, la biotipología se proponía distinguir "el estado de salud perfecta de la imperfecta, las verdaderas de las falsas robusteces", identificar todos los desequilibrios latentes que, si bien resultaban compatibles con un grado más o menos relativo de salud, colocaban a los individuos en los "confines de las enfermedades" (22 p.2).

En ese sentido, la vocación biotipológica por controlar a los "sanos", así como su disposición a detectar las morbosidades ocultas y latentes, eran particularmente afines con la tarea de "restauración" biológica que Carrillo (47 p.489) consideraba que debía desempeñar la política sanitaria para paliar las consecuencias de largos años de "incuria y de falta de previsión biológica" en el curso de los cuales se había dilapidado el capital humano legado por "nuestros fuertes y sanos antecesores". En este sentido, la salud laboral se problematizaba en la encrucijada entre la productividad y el declive. Al igual que los biotipólogos, para Carrillo (48 p.22) la política sanitaria debía "mejorar la eficiencia biológica del trabajador". Pero, al mismo tiempo, el combate contra el "mal" del ausentismo que el peronismo encaró, se entendía como un capítulo de una lucha más general contra la decadencia biológica, la desvitalización y desvalorización de la población. Para esa mentalidad, el ausentismo adquiría la significación de una suerte de "caldo de cultivo" de patologías que se incubaban lentamente y daba cuenta, en tanto prueba objetiva, del proceso progresivamente degenerativo que afectaba a la especie humana. Así, a través del método de la "radiografía integral" (practicado por el médico Edmundo Ingber, uno de los colaboradores de Carrillo), se descubría que el ausentismo por enfermedad, si bien respondía a causas psicológicas y sociales, tenía un fondo más grave de lo que "prima facie" parecía (47 p.489).

Para la medicina del trabajo de inspiración biotipológica el conocimiento integral del sujeto resultaba fundamental, no tanto para encontrar pruebas objetivas de la decadencia biológica, sino para anticiparse a la producción de accidentes y enfermedades.
La prevención eficaz de los accidentes dependía de la detección oportuna, mediante una batería de exámenes y tests, de las "diátesis" o "predisposiciones" que hacían a ciertos trabajadores más propensos a sufrir accidentes, trastornos o enfermedades, que a otros. Si bien las diátesis eran expresión de factores hereditarios trasmitidos por los padres, cierto "intervencionismo" biotipológico resultaba justificado porque, según Pende, los factores ambientales también ejercían una influencia (aun accesoria) sobre el plano hereditario.

De esta manera, se ofrecía una explicación de los accidentes y enfermedades harto conveniente para los empleadores, ya que la biotipología atribuía al medio fabril el rol de un factor "revelador o precipitante" de estados anormales más o menos latentes.

El organismo no recibe ciegamente la enfermedad como un huésped pasivo, sino que él mismo hace la enfermedad elaborándola con sus insuficiencias intrínsecas. (29 p.141)

Cada trabajador, por sus condiciones físico-psíquicas tiene una manera propia para reaccionar a las distintas sensaciones, pues la constitución individual o biotipo [...] predispone en una manera distinta a los accidentes del trabajo. (29 p.354)

Boccia, siguiendo a Gemelli, estaba convencido de que, más allá de la influencia de los factores exógenos o medioambientales, los accidentes se debían fundamentalmente a causas internas o subjetivas. Desde esa perspectiva, los factores subjetivos que intervenían en la causación del accidente no se articulaban en términos de acciones, comportamientos o conductas, sino que se pensaban en términos identitarios. La "accidentabilidad" se consideraba como un rasgo de identificación que permitía la clasificación de los individuos. Si de la indagación del biotipo del trabajador surgía que estaba "normalmente constituido", tanto en la esfera somática como psíquica, el accidente debía atribuirse al medio. Pero también existía un segundo grupo de individuos, en los cuales ciertas desviaciones de la normalidad fisiológica o psíquica los predisponían a sufrir accidentes.

La idea de que existía una "predisposición a los accidentes de trabajo" no era privativa 
de la biotipología. Por el contrario, se había desarrollado también en el campo de la psicología aplicada que inspiraba las investigaciones de Juan Kaplan. De hecho, la definición de la propia noción de "predisposición a los accidentes de trabajo" que aparece en los trabajos de Boccia, es idéntica a la que Kaplan (46) incluye en sus numerosos artículos: el conjunto de circunstancias que entre un grupo de individuos en condiciones iguales de trabajo, hace que algunos de los mismos sufran mayor número de accidentes, debido a las deficiencias orgánicas o funcionales de carácter físico o psíquico.

En fin, por esta vía la biotipología mostraba una faceta más de su funcionamiento como una auténtica técnica de predicción de la performance: no solo servía para anticiparse al rendimiento, seleccionando a los trabajadores que se mostraran más fuertes y resistentes frente a distintas causalidades dañinas, sino que también permitía predecir la producción de comportamientos que acarrearan accidentes, en la medida en que la "accidentabilidad" estaba inscripta en la personalidad. ¿Desde qué modelo pensaban entonces los biotipólogos al trabajador?

\section{LA CONCEPCIÓN DEL TRABAJADOR: ENTRE LA "PERSONALIDAD" Y EL "MOTOR HUMANO"}

Contra el dualismo cartesiano, que no había acertado en descifrar las leyes que vinculaban soma y psique, la biotipología defendía la unidad fundamental del hombre. Una batería de exámenes y tests aseguraban la objetivación de lo humano en términos de "constitución", "individualidad" y "personalidad" (23 p.12). Justamente, la innovación del método pendeano había consistido en reinstalar en el campo médico la perspectiva "sintética" que caracterizaba a la escuela constitucionalista, en contra de la mirada "localista" y reduccionista del "clasicismo médico" (23 p.12). Al hablar de "personalidad", los biotipólogos deseaban incluir en el campo de la medicina todas aquellas dimensiones -emotivas, psíquicas, sociales y espirituales- que el modelo médico dominante dejaba de lado. En contra del reduccionismo biologicista, no solo atribuían al ser humano una interioridad y hasta un fondo espiritual incognoscible, sino que defendían el carácter "indesglosable" de la personalidad psíquica y física. Sobre la convicción de la unidad integral del hombre se levantaba su vocación correlacionalística, su ánimo por encontrar las repercusiones, las resonancias, del mal de vivre en el cuerpo y, a la inversa, la clave de un comportamiento irregular y defectuoso, en los arcanos de las diátesis. Ello hacía que toda medicina fuera, en alguna medida, "psicosomática", que estuviera atenta a la recíproca influencia de lo psíquico y lo físico.

La inclusión de esa dimensión "psi" inauguraba una nueva agenda para la medicina del trabajo que debía encargarse de detectar en el ambiente fabril los factores "emotivógenos" capaces de producir síndromes psicosomáticos. Ello no dejaba de generar toda una serie de tensiones con el biologicismo imperante; de allí que, para justificar la presencia de tales preocupaciones en sus cursos, Boccia (45) debió aclarar que, aun siendo un clínico general, su formación estaba ligada a la escuela biotipológica. Asimismo, esa inclusión de la dimensión psíquica debía traducirse, para el médico italiano, en el plano de las políticas de asistencia al trabajo; en síntesis, en la organización de nuevos dispositivos para el control de la fuerza de trabajo, como los "comedores industriales, los recreos, las colonias marinas o de montaña", las instituciones deportivas, los "post-trabajo": un conjunto de organismos que cubrieran las pausas de la labor diaria y los días de reposo, dedicados a la recreación del espíritu y al reforzamiento de las energías (45 p.14).

De esta manera, la biotipología (junto con la medicina psicosomática, las restantes escuelas constitucionalistas, el humanismo médico, etc.) se presentaba como una expresión más del holismo médico de entreguerras (26), caracterizado, en este caso, por pensar al cuerpo humano en una forma sistémica, enfatizando las interconexiones entre las diversas "facetas" del biotipo; por instituir a la "personalidad", al ser humano integralmente considerado como el objeto de la mirada médica; por articular el conocimiento y la práctica médica como un acto de "síntesis" y sostener una perspectiva interdisciplinaria de la enfermedad y la salud.

A pesar de su holismo, los escritos de los biotipólogos no pudieron escapar a la metáfora 
del "motor humano" y al lenguaje dinámico de la "energía" que inspirara el pensamiento de la ciencia europea del trabajo, así como las utopías sociales e ideologías políticas de comienzos de siglo XX. Bajo diferentes formas, el comunismo, el taylorismo y el fascismo concebían al cuerpo como una fuerza productiva y un instrumento político, cuyas energías podían ser sometidas a alguna organización científicamente diseñada.

Así, en los escritos de Donato Boccia, la concepción holista coexistía con otra de corte fisicalista-materialista (pero igualmente idealista, en su promesa de optimizar la productividad) que inscribía al trabajo humano en las leyes generales de la termodinámica. $Y$ es que, como señala Rabinbach (21 p.3), el "productivismo moderno" -es decir, la creencia de que la sociedad humana y la naturaleza están ligadas por la primacía y la identidad de toda la actividad productiva, sea la de trabajadores, máquinas o fuerzas naturales- se fundó conceptualmente en la revolución científica que significó, en el siglo XIX, el descubrimiento de las leyes de la termodinámica (o).

En sus cursos, Boccia definía al organismo humano como un "motor" que, al igual que el mecánico, transformaba energía, es decir, producía trabajo. La propia medicina del trabajo se presentaba como una suerte de dispositivo coadyuvante de la primera ley de la termodinámica, en tanto prometía establecer las previsiones para conservar las "energías productivas" del ser humano (29 p.29). Sin embargo, también esta medicina biotipológica (como las ciencias del trabajo europeas con las que entró en diálogo y se nutrió) estaría capturada por la metáfora opuesta de la inevitable declinación, disolución y extenuación de la energía que, en relación al trabajo humano, se articuló bajo la forma de "fatiga". Boccia no solo conocía, sino que recuperaba en sus tratados y cursos de medicina del trabajo las "hermosas experiencias" de Palacios (38). La posibilidad de registrar mediante el ergógrafo creado por Mosso (p) "una de las cosas más íntimas y más características del individuo, vale decir, la manera como nos cansamos" (29 p.45), no podían sino seducir a un proyecto obsesionado con la personalización.

Pero tampoco la biotipología fue totalmente consecuente con el holismo médico que impregnaba sus discursos, por razones diversas a la internalización de la metáfora del motor humano. El "reduccionismo" que atacaba, irrumpía por varios frentes, en la medida en que, para personalizar las enfermedades, los accidentes y también la salud, recurrían, al mismo tiempo, a la noción de herencia y a una multiplicidad de tecnologías (antropometría, análisis de sangre, radiología integral, mediciones de las funciones endócrinas, etcétera). No menos reduccionista era la pretensión de estudiar la "individualidad", descuartizando al ser humano en varias facetas (las famosas "caras" de la pirámide biotipológica de Pende), para luego reconstituirlo, integrando y correlacionando los datos acumulados en la investigación de cada de ellas.

Idéntico reduccionismo transpiraba la obsesión por la elaboración de "biotipos" que, por su carácter ideal, generaban tensiones con la idea de individualidad (49 p.220); una obsesión de la que no escapó, tampoco, el peronismo: el propio Carrillo había atribuido el estudio del "hombre argentino" a una comisión especial y consideraba que el trabajo de establecer "un biotipo argentino ideal, somático, visceral y psíquico" debía ser continuado por el Instituto de Biotipología o Instituto del Hombre Argentino (50 p.1199).

El trabajo de tipologización no era privativo de los cultores de la antropometría o la biotipología, sino que encontraba expresión, asimismo, en el campo de la psicología y la psiquiatría, saberes comprometidos en la configuración de "perfiles" que habían dejado su huella, también, en la medicina del trabajo. Así, Boccia proponía utilizar la constitución de "perfiles" para la orientación y selección profesionales, entendiéndolos como una "representación esquemática sintética de la personalidad del sujeto". El perfil sería "psicotécnico cuando representa las calidades psicológicas del sujeto: será biotipológico cuando, además de las calidades psicológicas, representa también las calidades morfofuncionales del sujeto" (36 p.297).

\section{A MODO DE CONCLUSIÓN}

En la actualidad, una de las ideas a las que se apela para domeñar el conflicto entre 
productividad y salud, es la afirmación de que la productividad empresarial y la salud y seguridad laboral se vinculan de manera "virtuosa", "positiva" y "sinérgica". Ese punto de vista constituye una suerte de "sentido común tecnocrático", en torno al que confluyen varios discursos, cuyos agentes de enunciación (la Organización Internacional del Trabajo, el Banco Interamericano de Desarrollo, la Superintendencia de Riesgos del Trabajo, etc.) desempeñan roles estratégicos en la organización, regulación y control de los procesos de trabajo y los mecanismos de protección de la salud (51-54).

Más allá de la relativa rareza que tal articulación exhibe en el presente, que debe buscarse menos en la evidencia científica que la sustenta y más en las tecnologías, vocabularios y racionalidades a los que se apela para construirla, la misma no es totalmente novedosa.

Ya en la década del 30, los cultores de la biotipología en la Argentina presuponían, como explicamos a lo largo del artículo, que "productividad" y "salud" se ajustan de manera armoniosa; $y$, al igual que los tecnócratas actuales, esgrimían una serie de argumentos científicos para defender tal idea. Claro que a diferencia del presente, el carácter virtuoso de ese vínculo no venía dado por lo que la salud y la seguridad representaban en términos de "calidad" (del producto, de los procesos y sistemas), ni tampoco se probaba mediante cálculos financieros.

Por el contrario, los biotipólogos creían que el lugar en el que la productividad capitalista se encontraba con la salud de los trabajadores era esencialmente biológico. Al mismo tiempo, lo que aseguraba el mayor rendimiento y la mayor eficiencia biológica del capital humano desde la perspectiva de los empleadores, pero también del Estado-Nación, era la organización del trabajo según los criterios biotipológicos y psicotécnicos. Acercando la medicina y la psicología a las fábricas, conectándolas con dispositivos pedagógicos (escuelas, institutos de orientación y selección profesional), la biotipología se propuso aportar una solución al "formidable problema" (16 p.670) de la preparación y la distribución de los trabajadores en las sociedades burguesas.

Desde el punto de vista del poder, la operación no podía ser más económica: en tanto resultado de un mecanismo guiado por un conocimiento singularizado que ponderaba aptitudes, destrezas y debilidades personales, el lugar asignado a cada individuo se presentaba como "natural", ocultándose la dimensión políticoautoritaria del proceso y desalentándose, a priori, las resistencias.

A través de la selección y orientación profesional, la biotipología no solo se consideraba capaz de colocar a cada cuerpo allí donde resultara más productivo, más "operoso" desde el punto de vista del capital y del Estado sino que, además, prometía volver significativa la actividad laboral, revalorizar los oficios manuales y proporcionar, por vía de la experiencia de la capacidad, alegría y satisfacción a los trabajadores.

Mientras los biotipólogos defendían la posibilidad de arribar, mediante las armas de la ciencia, a un encastre virtuoso entre productividad y salud, la crítica que Bartolomé Bosio dirigió a ese tipo de propuestas pasaba por exhibir la realidad de un conflicto entre la búsqueda capitalista de ganancias y la salud de los trabajadores, que ninguna medicina o psicología podía salvar. Su denuncia consistía en afirmar que, al capitalista, lo único que le importaba era el rendimiento al menor costo, "sin importar el deterioro, sin importar que el motor humano se gaste pronto porque siempre tienen a mano a otros motores humanos, y tal vez a más bajo precio" (32 p.915). Contra la utopía de la "humanización" del trabajo, Bosio introdujo en el debate con los biotipólogos, la realidad de la sociedad capitalista:

\footnotetext{
Quienes organizan el trabajo son los dueños de la economía no los biotipólogos. Y la organización que le dan [...] responde a lo que persiguen sus organizadores: la mayor productividad en todo sentido, sin preocuparse, de inmediato, por la suerte de los que trabajan. (32 p.913-914)
}

Ciertamente, los esfuerzos que desde diversos lugares de enunciación y práctica se realizan en la contemporaneidad para demostrar que la productividad y la salud se vinculan de manera virtuosa están muy lejos de constituir una reverberación de la utopía autoritaria que encerraba el "cada uno en su justo lugar" de los biotipólogos. Sin embargo, también en estos esfuerzos del presente se aloja una aspiración funcionalista que, como la biotipológica del siglo $\mathrm{XX}$, apunta a suturar el conflicto. 


\section{NOTAS FINALES}

a. En términos generales, la eugenesia moderna tiene por objeto la implementación de medidas para el mejoramiento de la descendencia humana, a través de la reproducción diferencial de ciertos individuos o grupos considerados valiosos o mejores $y$, en algunas versiones (eugenesia negativa) por medio de la interferencia sobre la reproducción de seres que supuestamente tendrán hijos con enfermedades hereditarias graves (1 p.115-116).

b. Por razones de espacio no podemos citar toda la bibliografía historiográfica que en los últimos años se ha ocupado del desarrollo de la eugenesia en la Argentina. Véase, sobre el punto, los artículos compilados por Marisa Miranda y Gustavo Vallejo (2). Asimismo, la eugenesia ha sido abordada como un capítulo de problematizaciones más generales dedicadas a los debates demográficos (3), la historia de la tuberculosis en la ciudad de Buenos Aires (4), el reformismo liberal (5), la higiene mental (6), entre otros temas.

c. Aclaramos que, a lo largo del artículo (sea en el cuerpo principal del texto o en las notas), solo incluiremos las referencias biográficas que consideramos fundamentales para la comprensión de los argumentos centrales del mismo. Así, Arturo Rossi, director de los Anales de la Asociación de Biotipología, Eugenesia y Medicina Social y uno de los creadores de la Escuela de Biotipología, fue durante la "década infame" (1930-1943) el líder de la biotipología argentina. En 1947 tradujo, junto a Donato Boccia, el Tratado de biotipología que Pende escribió en 1936 (15) y escribió un Tratado práctico de biotipología y ortogénesis (tres tomos), publicado en 1944 (16).

d. Dicho instituto se inauguró en Génova en 1926 bajo la dirección de Nicola Pende. Entre sus objetivos se encontraban: el control periódico del desarrollo físico, moral e intelectual de niños y adolescentes y de la constitución física y psíquica de los trabajadores, la psicotécnica, la orientación profesional, etcétera. Para un mayor desarrollo, ver los trabajos de Vallejo $(7,8)$.

e. Sobre el Instituto del Hombre, la labor de Alexis Carrel y la influencia de sus ideas en el país, ver Reggiani (18).

f. Este médico ítalo-argentino, formado en Italia con la escuela constitucionalista, jefe del servicio de clínica del Hospital Italiano de Buenos Aires, se convirtió, con el tiempo, en una suerte de referencia local de la medicina del trabajo. g. El término holismo está asociado con una pluralidad de significaciones. A lo largo de este artículo lo utilizaremos en dos sentidos divergentes que, si bien no se relacionan necesariamente, en el caso de los biotipólogos argentinos aparecen entremezclados. Nos referiremos a la biotipología como una expresión del "holismo médico" (26), un conjunto de movimientos (que incluye a todas las escuelas constitucionalistas: la medicina psicosomática, el humanismo católico, la medicina neohipocrática, etc.) desarrollados fundamentalmente en la Europa de entreguerras, en oposición al "reduccionismo" y a la excesiva confianza en la tecnología que esas perspectivas encontraban en el modelo médico dominante, crecientemente "biomédico". Pero también sostenemos que el pensamiento biotipológico está impregnado de holismo, en un segundo sentido "ideológico" del término. Como "ideología", el holismo designa al conjunto de ideas y valores comunes en una sociedad, que se caracteriza por valorizar la totalidad social y descuidar o subordinar al individuo humano (27 p.303). En cualquiera de los dos usos, la noción de holismo es intrínsecamente relacional, oponiéndose en el primer caso al "reduccionismo" médico y en el segundo al "individualismo".

h. Agostino Gemelli era un sacerdote jesuita antisemita, rector de la Universidad Católica de Milán, Presidente de la Academia Pontificia y el principal enlace entre el régimen fascista y el Vaticano. Dedicado al desarrollo de la psicotécnica, fue un estrecho colaborador de los biotipológos argentinos (8).

i. La creencia en la posibilidad de aumentar -a través de las herramientas de la ciencia- la productividad del trabajo y, su reverso, la constatación de una tendencia inescapable hacia la decadencia biológica y civilizatoria, constituyen una de las paradojas de la Modernidad, que impregnara y fuera abonada tanto por la biotipología como por el pensamiento eugenésico de Alexis Carrel (18), las investigaciones psicofisiológicas sobre la fatiga y la ciencia europea del trabajo, entre una multiplicidad de expresiones (21).

j. A partir de la década del 60, se fue imponiendo la noción "neoliberal" de capital humano entendido como el conjunto de aptitudes innatas y adquiridas consustanciales a la persona del trabajador que, debidamente aprovechadas, producen un flujo de beneficios. Mientras el capital humano, en sentido neoliberal, es inseparable del trabajador, el capital humano en sentido "holista" o también "poblacional" es un "activo" del Estado-Nación y cada trabajador, individualmente considerado, es solo una expresión parcial, molecular, del capital humano. 
k. Un detalle de cada una de estas propuestas se encuentra sintetizado en el artículo que publicaron en 1940 Giraldes y Ugarte proponiendo la libreta sanitaria del niño (34).

I. En la problematización de la "productividad" del trabajo y de su relación con los procesos de salud y enfermedad, la psicotécnica constituye todo un capítulo autónomo de indagación que excede los objetivos de este artículo. Si bien se trata de uno de los tópicos centrales de la biotipología del trabajo, la psicotécnica tal como la entendían los biotipólogos es solo una perspectiva entre una multiplicidad de enfoques y elaboraciones que se desarrollaron principalmente en el ámbito de la psicología experimental y aplicada desde la primera década y hasta mediados del siglo XX, tanto en Europa como en EE.UU. Para un desarrollo más extenso ver Rabinbach (21).

m. En 1923, el Ministerio de Justicia e Instrucción Pública de la Nación creó el Instituto de Psicotécnica y Orientación Profesional, designándose como director al Dr. Carlos Jesinghaus. El Instituto atendía consultas de orientación profesional individuales (en forma presencial o por carta) y realizaba exámenes médicos y psicotécnicos completos para determinar las aptitudes profesionales. Asimismo, desde 1928 impartía cursos regulares para formar "consejeros de orientación profesional" y publicaba la Guía de estudios superiores y la Cartilla de orientación profesional que se repartían entre las escuelas. En 1931, la partida del presupuesto nacional con la que se financiaba fue suprimida, lo que ocasionó el cese de las actividades. Ese mismo año, el Museo Social Argentino solicitó al Ministerio de Justicia la donación del material del laboratorio y estableció un Instituto de Orientación Profesional como uno de sus organismos, con el mismo personal técnico. En la décadas del 30 y del 40 se crearon gabinetes psicotécnicos -siguiendo el modelo del Instituto- en diferentes ciudades del país $(37,44)$.

n. Agradecemos a Karina Ramacciotti la referencia a Juan Kaplan, un médico especializado en higiene y medicina social, que se dedicó a cultivar la medicina del trabajo en la Argentina, y que incluía a la psicotécnica como un capítulo de esta. Kaplan conocía la biotipología e, incluso, aceptaba varios de sus presupuestos, pero su psicotécnica se inspiró en los desarrollos de la psicología aplicada, fundamentalmente, a la industria.

o. La ley universal de la conservación de la energía fue formulada en 1847 por Hermann von Helmholtz, un médico y fisiólogo alemán, pionero de la termodinámica, que sostenía que todas las fuerzas de la naturaleza (fueran estas de orden mecánico, eléctrico, químico o lo que fuesen) eran expresiones de una energía universal singular o Kraft, que no podía ser destruida. Casi simultáneamente Rudolf Clausius descubrió la segunda ley de la termodinámica, que sostiene la irreversibilidad y el declive de la energía bajo la forma de entropía (21 p.3).

p. Este fisiólogo italiano se convirtió en uno de los padres de los estudios experimentales sobre la fatiga. Su clásico La fatiga, publicado en 1891 estuvo muy influenciado por los descubrimientos de la termodinámica. Agradecemos a Gustavo Vallejo la sugerencia relativa al vínculo entre la grafología de Mosso, las investigaciones de Palacios y la biotipología en la Argentina.

\section{REFERENCIAS BIBLIOGRÁFICAS}

1. Palma H. Consideraciones historiográficas, epistemológicas y prácticas acerca de la eugenesia. En: Miranda M, Vallejo G, compiladores. Darwinismo social y eugenesia en el mundo latino. Buenos Aires: Siglo Veintiuno Editores; 2005. p. 115-144.

2. Miranda M, Vallejo G, compiladores. Darwinismo social y eugenesia en el mundo latino. Buenos Aires: Siglo Veintiuno Editores; 2005.

3. Zarini P. La utopía eugenista en la Argentina (1900-1950). En: Otero H, director. El mosaico argentino. Modelos y representaciones del espacio y de la población, siglos XIX-XX. Buenos Aires: Siglo Veintiuno Editores; 2004. p. 425-469.

4. Armus D. La ciudad impura. Salud, tuberculosis y cultura en Buenos Aires, 1870-1950. Buenos Aires: Edhasa; 2007.

5. Zimmermann E. Los liberales reformistas (1890-1915). Buenos Aires: Sudamericana; 1997.

6. Talak AM. Eugenesia e higiene mental: usos de la psicología en Argentina (1900-1940). En: Miranda M, Vallejo G, compiladores. Darwinismo social y eugenesia en el mundo latino. Buenos Aires: Siglo Veintiuno Editores; 2005. p. 563-599. 
7. Vallejo G. El ojo del poder en los espacios del saber. Asclepio. 2004;LVI(1):219-244.

8. Vallejo G. Las formas del organicismo social en la eugenesia latina. En: Miranda M, Vallejo G, compiladores. Darwinismo social y eugenesia en el mundo latino. Buenos Aires: Siglo Veintiuno Editores; 2005. p. 231-272.

9. Vallejo G, Miranda M. Los saberes del poder: eugenesia y biotipología en la Argentina del Siglo XX. Revista de Indias. 2004;LXIV(231):425-444.

10. Vallejo G, Miranda M. La eugenesia y sus espacios institucionales en Argentina. En: Miranda $M$, Vallejo G, compiladores. Darwinismo social y eugenesia en el mundo latino. Buenos Aires: Siglo Veintiuno Editores; 2005. p. 145-192.

11. Miranda M. La antorcha de Cupido: eugenesia, biotipología y eugamia en Argentina, 19301970. Asclepio. 2003;LV(2):231-255.

12. Miranda M. Prostitución y homosexualidad en Argentina: el discurso eugénico como sustrato teórico. En: Miranda M, Vallejo G, compiladores. Darwinismo social y eugenesia en el mundo latino. Buenos Aires: Siglo Veintiuno Editores; 2005. p. 451-496.

13. Boccia D. La ciencia de los tipos humanos según la escuela italiana. Anales de Biotipología, Eugenesia y Medicina social. 1933;(1):20-21.

14. Devoto F. Nacionalismo, fascismo y tradicionalismo en la Argentina moderna. Buenos Aires: Siglo Veintiuno Editores; 2006.

15. Pende N. Tratado de biotipología humana individual y social. Barcelona: Salvat; 1947.

16. Rossi A. Tratado teórico práctico de biotipología y ortogénesis. Buenos Aires: Ideas; 1944.

17. Ramacciotti K. Las huellas eugénicas en la política sanitaria argentina (1946-1955). En: Miranda M, Vallejo G, compiladores. Darwinismo social y eugenesia en el mundo latino. Buenos Aires: Siglo Veintiuno Editores; 2005. p. 311-350.

18. Reggiani AH. God's eugenicist: Alexis Carrel and the sociobiology of decline. New York: Berghahn Books; 2007.

19. Habermas J. El futuro de la naturaleza humana. ¿Hacia una eugenesia liberal? Barcelona: Paidós; 2002.
20. Reggiani AH. La ecología institucional de la eugenesia: Repensando las relaciones entre biomedicina y política en la Argentina de entreguerras. En: Miranda M, Vallejo G, compiladores. Darwinismo social y eugenesia en el mundo latino. Buenos Aires: Siglo Veintiuno Editores; 2005. p. 273-310.

21. Rabinbach A. The human motor. Berkeley: University of California Press; 1992.

22. Rossi A. La asistencia social en función de la medicina preventiva. Anales de Biotipología, Eugenesia y Medicina Social. 1939;(85):1-3.

23. Rossi A. Curso sintético de medicina constitucional y biotipología. Anales de Biotipología, Eugenesia y Medicina Social. 1933;(2):12-13.

24. Boccia D. Biotipología del trabajador. La Prensa Médica. 1949;(13):676-682.

25. Carrillo R. Conferencia inaugural del Sr. Secretario de Salud Pública de la Nación, Dr. Ramón Carrillo con motivo de la iniciación de los cursos en la Escuela de Biotipología y Ciencias Afines el $1^{\circ}$ de abril de 1947. Anales de la Secretaría de Salud Pública de la Nación. 1947;I(5).

26. Lawrence C, Weisz G. Medical holism: The context. En: Lawrence C, Weisz G, editors. Greater tan the parts. Holism in biomedicine 1920-1950. New York: Oxford University Press; 1998. p. 1-24.

27. Dumont L. Essais sur l'individualisme. France: Éditions du Seuil; 1991.

28. Sociedad Argentina de Biotipología, Eugenesia y Medicina Social. La Prensa Médica. 1932;(3):231-232.

29. Boccia D. Medicina del Trabajo. Buenos Aires: Establecimiento Tipográfico de Guidi Buffarini; 1938.

30. Miranda M. Bartolomé Bosio, un heterodoxo en el campo eugénico argentino en el período entreguerras. En: XII Jornadas Nacionales de Departamentos y Escuelas de Historia [CDROM]. San Carlos de Bariloche: Universidad Nacional del Comahue; 2009.

31. Bosio B. Breves consideraciones sobre los propósitos del primer Congreso de Sociología y Medicina del Trabajo. La Semana Médica. 1939;(49):1337-1339.

32. Bosio B. Biotipología y medicina del trabajo. La Semana Médica. 1940;(15):912-915. 
33. Foucault M. Seguridad, territorio y población. Buenos Aires: Fondo de Cultura Económica; 2006.

34. Giraldes DA, Ugarte F. La libreta sanitaria del niño. La Semana Médica. 1940;(9):527-533.

35. Carrillo R. Introducción al conocimiento de la salud pública. En: Contribuciones al conocimiento sanitario. Buenos Aires: Eudeba; 1974.

36. Boccia D. Tratado de medicina del trabajo. t. I. Buenos Aires: El Ateneo; 1947.

37. Kaplan J. Historia de la orientación y selección profesional en la República Argentina. Buenos Aires: Facultad de Ciencias Médicas de la Universidad de Buenos Aires; 1948.

38. Palacios A. La fatiga y sus proyecciones sociales. Buenos Aires: La Vanguardia; 1935.

39. Bazán F, Malamud T. Medicina Escolar. Fundamentos médicos y sociales para propiciar la vigencia de la ficha escolar. La Semana Médica. 1934;(35):621-625.

40. Padilla T. Certificado de Salud para el personal del servicio doméstico. Proyecto de Ley. La Semana Médica. 1934;(32):431-432.

41. Solá J. El carnet del obrero. La Semana Médica. 1932;(21):1605-1608.

42. Bossi LA. Normas para la práctica de prevención médico-social en las enfermedades profesionales. Anales de Biotipología, Eugenesia y Medicina social. 1940;(93):19-22.

43. Clusellas F. Medicina Social del Trabajo. La Semana Médica. 1941;(8):462-475.

44. Olives A. Los problemas de la psicotécnica. La selección y la orientación profesional. Anales de Biotipología, Eugenesia y Medicina Social. 1936;(66):7-8
45. Boccia D. Medicina psicosomática y medicina del trabajo. Buenos Aires: Alfa; 1953.

46. Kaplan J. Medicina del Trabajo. Buenos Aires: El Ateneo; 1952.

47. Carrillo R. Estado actual del problema de la revitalización. La Semana Médica. 1949;(15 sep):475-490.

48. Carrillo R. Higiene y Medicina Social. Anales de la Secretaria de Salud Pública de la Nación. 1947;III(19):22-34.

49. Barcillos Ferreira A. Constitución. La Semana Médica. 1944; (Tomo Cincuentenario):215-221.

50. Carrillo R. Plan esquemático de salud pública (1952-1958). La Semana Médica; 1951;(27 dic). $1187-1201$

51. Iunes R. Salud ocupacional y desarrollo económico. En: Oliva F, compilador. Semana Argentina de Salud y Seguridad en el Trabajo. Presentaciones 2004. Buenos Aires: SRT; 2005.

52. Forastieri V. La participación de los trabajadores en materia de seguridad y salud en el trabajo en el ámbito de la OIT. En: Superintendencia de Riesgos del Trabajo. Aportes para el debate de la Reforma de la Ley de Riesgos del Trabajo. La participación como instrumento de promoción al diálogo social. Buenos Aires: SRT; 2007. p. 95-108.

53. Hiba JC. Cómo mejorar las condiciones de trabajo y la productividad en empresas agrícolas y agroindustriales. Guía para la acción. [Internet] Buenos Aires: FUSAT-OIT, 2005 [citado 6 may 2011]. Disponible en: www.oit.org.ar/pagina.php? seccion $=49 \&$ pagina $=178$.

54. Superintendencia de Riesgos del Trabajo. Lineamientos Estratégicos. Buenos Aires: SRT; 2003.

\section{FORMA DE CITAR}

Haidar V. "Todo hombre en su justo lugar": la "solución" biotipológica al conflicto entre productividad y salud (Argentina, 1930-1955). Salud Colectiva. 2011;7(3):317-332.

Recibido el 9 de mayo de 2011

Versión final presentada el 14 de julio de 2011

Aprobado el 25 de julio de 2011 